\title{
Reconstituição paleoambiental das formações Motuca e Sambaíba, Permo-Triássico da Bacia do Parnaíba no sudoeste do Estado do Maranhão, Brasil
}

Paleoenvironmental reconstitution of Motuca and Sambaiba formations, Permian-Triassic of the Parnaiba Basin in southwest Maranhão state, Brazil

\author{
Francisco Romério Abrantes Júnior ${ }^{1}$, Afonso César Rodrigues Nogueira \\ ${ }_{1}^{1}$ Programa de Pós-graduação em Geologia e Geoquímica, Instituto de Geociências, Universidade Federal do \\ Pará - UFPA, Rua Augusto Corrêa s/n, CEP 66075-110, Belém, PA, Brasil (jrabrantes@hotmail.com; anogueira@ufpa.br)
}

Recebido em 22 de janeiro de 2013; aceito em 24 de maio de 2013

\begin{abstract}
Resumo
O intervalo que compreende o final do Paleozoico e início do Mesozoico foi marcado por mudanças globais paleogeográficas e paleoclimáticas, em parte atribuídas a eventos catastróficos. A intensa continentalização do supercontinente Pangeia, com a implantação de extensos desertos, sucedeu os ambientes costeiro-plataformais do início do Permiano. Os registros desses eventos no norte do Brasil são encontrados nas bacias intracratônicas, particularmente na sucessão Permotriássica da Bacia do Parnaíba. A análise de fácies e estratigráfica de afloramentos desta sucessão permitiu a individualização de 14 fácies sedimentares agrupadas em 4 associações de fácies (AF): AF1 e AF2, relacionadas aos depósitos da Formação Motuca, e AF3 e AF4, representativas da base da Formação Sambaíba. A AF1 - Lacustre raso/Mudflat consiste em pelitos vermelhos laminados com lentes de gipsita, calcita e marga, além de lobos de arenitos sigmoidais. A AF2 - Saline pan é constituída por corpos lenticulares de gipso laminado, gipso nodular e gipsarenito, sobrepostos por pelitos esverdeados com nódulos de dolomita e palygorskita. A AF3 - Lençol de areia e AF4 - Campo de dunas são formadas, respectivamente, por arenitos de coloração creme alaranjada com estratificação plano-paralela e estratificação cruzada de médio a grande porte. Destaca-se o registro de intervalos deformados lateralmente contínuos por centenas de quilômetros na zona de contato entre as formações Motuca e Sambaíba. Nestes, ocorrem pelitos com camadas contorcidas e brechadas (Formação Motuca) e arenitos com falhas/microfalhas sinsedimentares, laminação convoluta e diques de injeção preenchidos por argilitos (Formação Sambaíba), interpretados como sismitos induzidos por terremotos de alta magnitude ( $>8$ na escala Richter).
\end{abstract}

Palavras-chave: Formação Motuca; Formação Sambaíba; Bacia do Parnaíba; Análise de fácies; Paleoambiente.

\begin{abstract}
The interval between the Late Paleozoic and Early Mesozoic was marked by paleogeographic and paleoclimatic global changes, partly attributed to catastrophic events. The intense continentalization of the supercontinent Pangaea of End-Permian propitiated the development of extensive deserts that succeeded the coastal and platform environments of Early Permian. The records of these events in northern Brazil are found in intracratonic basins, particularly in the Permo-triassic succession of the Parnaíba Basin. The facies and stratigraphic outcrops analysis of this succession allowed the individualization of 14 sedimentary facies grouped into four facies associations (FA): FA1 and FA2 related to deposits of Motuca Formation and, FA3 and FA4, representative of the base of Sambaíba Formation. The FA1 - Shallow lake/Mudflat consists of red laminated mudstone with lenses of gypsum, calcite and marl, besides lobes of sigmoidal sandstones. The FA2 - Saline pan consists of lenticular bodies of laminated gypsum, nodular gypsum and gypsarenite, overlapped by greenish mudstones with dolomite nodules and palygorskite. The FA3 - sand sheet and FA4 - dunes field are formed, respectively, for orange cream sandstones with even parallel stratification and medium- to large-scale cross-bedding. In the contact between Motuca and Sambaíba formations occurs a deformed interval, laterally continuous for hundreds of kilometers. Brecciated and contorted bedded siltstones and mudstone (Motuca Formation) and sandstone with sinsedimentary faults/microfaults, convolute lamination and mud-filled injection dykes (Sambaíba Formation) are interpreted as seismites triggered by high magnitude earthquakes ( $>8$ according Richter scale).
\end{abstract}

Keywords: Motuca Formation; Sambaíba Formation; Parnaíba Basin; Facies analysis; Paleoenvironment. 


\section{INTRODUÇÃO}

O conhecimento estratigráfico da Bacia do Parnaíba, alavancado principalmente pelas companhias de petróleo no final do século passado, tem sido revisado nos últimos anos, principalmente pela sua potencialidade à acumulação de hidrocarbonetos. Além disso, trabalhos de mapeamento geológico promovidos por instituições de ensino têm permitido desvendar particularidades da história sedimentar. Nessa bacia, um dos intervalos mais importantes - e ainda pouco conhecido - é o Permotriássico. Apesar dos registros catastróficos globais dados pela ocorrência de algumas feições de impacto de meteorito e vulcanismo, ainda é incipiente o quanto esses eventos influenciaram na sedimentação. A sucessão Permotriássica da Bacia do Parnaíba, objeto de investigação deste estudo, é representada pelos depósitos siliciclásticos e evaporíticos das formações Motuca e Sambaíba, que também registram importantes mudanças paleogeográficas e paleoclimáticas globais relacionadas à intensa continentalização da Pangeia (Zharkov e Chumakov, 2001; Keller, 2005). A análise de fácies e estratigráfica de afloramentos da referida sucessão na região de Filadélfia (TO) a Loreto (MA) permitiu desvendar o paleoambiente, bem como tecer condições paleoclimáticas e paleogeográficas, contribuindo no entendimento do Permotriássico da porção SW da Bacia do Parnaíba (Figura 1).

\section{CONTEXTO GEOLÓGICO}

\section{Bacia do Parnaíba}

A Bacia Intracratônica do Parnaíba apresenta espessura máxima de $3.400 \mathrm{~m}$, ocupando uma área de aproximadamente $600.000 \mathrm{~km}^{2}$, que abrange os estados do Maranhão, Piauí e parte dos estados do Pará, Tocantins e Ceará. Desenvolveuse sobre um embasamento continental fortemente estruturado, representado por rochas formadas ou retrabalhadas no Ciclo Brasiliano do Cinturão Araguaia-Tocantins, da Faixa Gurupi, dos crátons Amazônico e São Francisco e da Província Borborema (Cunha, 1986). Encontra-se limitada a norte pelo Arco Ferrer-Urbano Santos; a leste, pela Falha de Tauá; a sudeste, pelo Lineamento Senador Pompeu; a oeste, pelo Lineamento Tocantins-Araguaia; e, a noroeste, pelo Arco Tocantins (Góes, 1995).

A sedimentação na Bacia do Parnaíba ocorreu inicialmente em consequência da atuação de um megassistema de fraturas, associado à subsidência crustal de uma grande área cratônica, que ocorreu do final da Orogenia Brasiliana até a Orogenia Caledoniana da Cordilheira Andina (Siluriano-Devoniano). Essa sedimentação, que perdurou até o Neotriássico, foi interpretada na forma de três sequências (ou ciclos) deposicionais limitadas por discordâncias regionais, representadas pelos grupos Serra Grande (Ordoviciano-Devoniano Inferior), Canindé (Devoniano Superior-Carbonífero Inferior) e Balsas (Carbonífero Superior-Triássico Inferior). O Grupo Balsas é composto pelas formações Piauí, Pedra de Fogo, Motuca e Sambaíba, que representam um ambiente clástico-evaporítico de mar raso, gradando para ambiente lacustre/desértico (Vaz et al., 2007).

A Formação Motuca foi designada por Plummer et al. (1948) para os folhelhos avermelhados, com lentes de calcário e anidrita que afloram na Fazenda Motuca, entre São Domingos e Benedito Leite (MA). Melo e Prade (1968) propuseram a subdivisão dessa formação em três membros: o Membro Inferior, constituído essencialmente por arenitos finos a muito finos de coloração vermelho-tijolo; o Membro Médio, formado por intercalações de siltitos com bancos carbonáticos, em geral sucedidos por camadas mais espessas de gipsita e/ou anidrita; e o Membro Superior, constituído dominantemente por arenitos muito finos a siltitos vermelhos. A sedimentação Motuca é interpretada como um sistema desértico com lagos associados. O contato inferior com a Formação Pedra de Fogo é concordante, enquanto o contato superior com a Formação Sambaíba é descrito como gradativo, mas localmente brusco e erosivo (Góes e Feijó, 1994).

A Formação Sambaíba foi definida primeiramente por Plummer et al. (1948) para caracterizar os arenitos que constituem mesetas observadas nas adjacências da cidade homônima. Essa unidade é representada por arenitos com estratificações planares e cruzadas acanaladas de grande porte (Aguiar, 1971). Esses arenitos com estratificação cruzada de grande porte, contendo diversas feições típicas de sedimentos eólicos, caracterizam um sistema desértico, com contribuição fluvial (Vaz et al., 2007). O contato superior da Formação Sambaíba se dá com os derrames básicos do Eojurássico da Formação Mosquito (Góes e Feijó, 1994).

\section{Eventos globais na passagem Permiano-Triássico}

A transição do Permiano para o Triássico foi marcada pela mudança de um clima glacial (Carbonífero-Eopermiano) para um clima quente com variações relativas da umidade e crescente aridez no Pangea, concomitante com a extinção em massa da fauna e/ou flora marinha e terrestre. A paleogeografia da Pangeia mudou drasticamente com a progressiva elevação das porções centrais do continente, ocasionando o recuo gradual do mar, que, juntamente com o degelo das calotas polares, resultou na aridez crescente de zonas interiores em latitudes baixas a médias e no deslocamento do semiárido para os polos (Parrish et al., 1986; Zharkov e Chumakov, 2001). A porção setentrional da América do Sul foi afetada pela orogenia Allegheniana, 


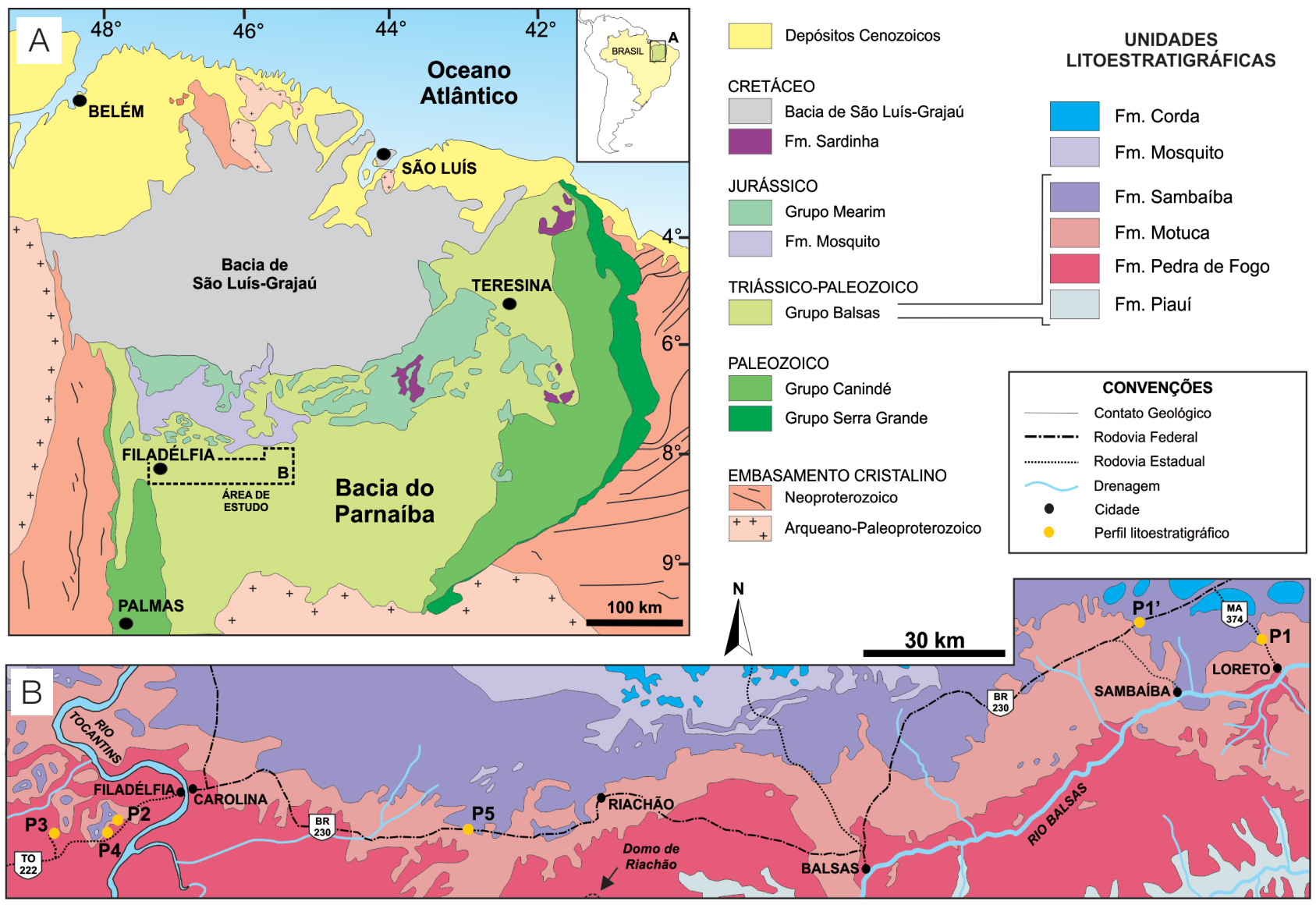

Figura 1. A Bacia do Parnaíba. (A) Contexto geológico regional. (B) Mapa geológico simplificado da área de estudo com a localização dos perfis litoestratigráficos.

relacionada à colisão final dos continentes Laurásia e Gondwana, resultando em soerguimentos generalizados e deflexões locais (processo de flambagem; subsidência) que propiciaram a acumulação de sedimentos na Bacia do Parnaíba (Zalán, 1991). O clima árido a semiárido influenciou a formação de depósitos eólicos, red beds lacustres-aluviais, lagoas salinas, evaporitos, planícies de sabkhas costeiros e continentais (Glennie e Buller, 1983).

A extinção em massa Permotriássica ocorreu durante este intervalo de Hot House, marcado pelo aquecimento global generalizado na Pangeia, que foi intensificado pelas erupções das Armadilhas Siberianas (Siberian Traps) (Erwin, 1994, 1999; Bowring et al., 1998; Keller, 2005).Esse evento culminou com a mortandade de aproximadamente $90 \%$ de todas as espécies marinhas e uma enorme redução dos vertebrados e plantas terrestres, bem como o desenvolvimento expressivo de fungos decompositores (fungal spike) (Sepkoski, 1986; Erwin, 1993, 1994; Twitchett et al., 2001; Steiner et al., 2003). Indicadores geoquímicos, mineralógicos e litológicos no Permiano-Triássico sugerem a possibilidade de impacto extraterrestre no megacontinente Pangeia, que pode ter contribuído com a extinção nesse intervalo (Bice, 1992; Kerr, 1996; Retallack et al., 1998). As principais evidências foram encontradas na Austrália, na Antártida e no Brasil, sendo descritas anomalias de elementos do grupo da platina (irídio e ósmio), grãos de quartzo de impacto (shocked quartz), shatter cones, bombas hematíticas e kink bands em diversos minerais (Retallack et. al., 1998; Crósta, 2002; Tohver et al., 2012).

\section{MÉTODOS}

A análise de fácies seguiu a técnica de modelamento de fácies proposta por Walker (1992) e Miall (1991, 1994), que envolve a individualização e descrição de fácies, caracterizando composição, geometria, texturas, estruturas sedimentares, padrões de paleocorrente e processos sedimentares, agrupando-as em associações de fácies contemporâneas e cogenéticas, que refletem os diferentes ambientes e sistemas deposicionais. Análises mineralógicas (difratometria de raios-X) e petrográficas foram utilizadas 
como informações complementares para as interpretações paleoambientais e paleoclimáticas da sucessão estudada.

\section{A SUCESSÃO PERMOTRIÁSSICA DA BACIA DO PARNAÍBA}

\section{Aspectos gerais}

A sucessão sedimentar estudada das formações Motuca e Sambaíba ocorre em afloramentos lateralmente contínuos, em cortes de estrada, localizados às margens da rodovia estadual MA-374, na região de Loreto (MA), da rodovia federal BR-230 na região de Riachão (MA) e em pedreiras de extração de gipso na região de Filadélfia (TO) (Figura 1). Os perfis estudados possuem espessuras que variam de 12 a $27 \mathrm{~m}$, porém os depósitos da Formação Sambaíba alcançam até $400 \mathrm{~m}$ nas mesetas sedimentares encontradas na área. Colúvios e a densa cobertura vegetal na região dificultam a observação do contato entre as formações (Figura 2).

A Formação Motuca é constituída predominantemente por pelitos vermelhos laminados com lentes de gipsita, calcita e marga. Na porção leste da Bacia do Parnaíba, as fácies tornam-se mais arenosas com a ocorrência expressiva de arenitos com estratificação cruzada sigmoidal. A Formação Sambaíba consiste em arenitos de coloração creme alaranjada com estratificação plano-paralela e estratificação cruzada de médio a grande porte. Em geral, o contato entre as unidades é brusco, representado pela passagem de arenitos finos com laminação cruzada cavalgante e acamamento flaser/wavy da Formação Motuca para arenitos médios com falhas/microfalhas sinsedimentares e laminações convolutas da Formação Sambaíba (Figura 3).

No intervalo estudado, foram individualizadas 14 fácies sedimentares, agrupadas em quatro associações, relacionadas a um sistema desértico, sendo representados por depósitos lacustres rasos de clima árido (sabkha continental com saline pans associadas), depósitos fluviais efêmeros, depósitos eólicos de lençol de areia e de campo de dunas (Tabelas 1 e 2).

\section{Associações de fácies da Formação Motuca}

\section{Lacustre raso/Mudflat (AF1)}

A AF1 corresponde aos maiores e mais expressivos depósitos da Formação Motuca, sendo constituída pelas fácies pelito laminado (Pl), arenito com laminação cruzada cavalgante (Al), arenito com estratificação cruzada sigmoidal (Asg), arenito maciço (Am), ritmito arenito/pelito (Rap), marga maciça $(\mathrm{Mm})$ e calcário maciço $(\mathrm{Cm})$. Nos perfis estudados, esta associação abrange uma sucessão de até $10 \mathrm{~m}$ de espessura, com mudanças laterais nos conjuntos de fácies (Cf).
A leste, ocorre o predomínio da fácies $\mathrm{Pl}$ associada com as fácies Asg, Am e Rap (Cf1), ao passo que, a oeste, associase às fácies $\mathrm{Mm}$ e $\mathrm{Cm}$ (Cf2). A porção superior desses depósitos é marcada pela passagem brusca de arenitos finos com laminação cruzada $(\mathrm{Al})$ para arenitos médios deformados de lençol de areia (AF3). Inferior a todos esses depósitos, a fácies $\mathrm{Pl}$ ocorre de maneira homogênea, contínua lateralmente por vários quilômetros e verticalmente até o contato inferior com a Formação Pedra de Fogo.

O Cf1 é composto por camadas tabulares de pelito laminado de coloração avermelhada (Pl), ritmito arenito/pelito (Rap) e camadas de arenitos médios a grossos, moderadamente selecionados, com geometria de lobo sigmoidal com estruturação complexa (Asg) e tabular maciça (Am), configurando ciclos coarsening upward de escala métrica (Figura 4). Os sets de estratificação cruzada sigmoidal variam de 10 a $30 \mathrm{~cm}$ de espessura e são lateralmente contínuos por até $12 \mathrm{~m}$. O Cf2 consiste em camadas tabulares métricas de pelito laminado $(\mathrm{Pl})$ e centimétricas de marga maciça $(\mathrm{Mm})$ e calcário maciço $(\mathrm{Cm})$. As camadas de $\mathrm{Mm}$ e Cm são contínuas lateralmente por até $20 \mathrm{~m}$ e limitam ciclos shallowing upward.

A AF1 foi depositada dominantemente por processos de decantação em um extenso ambiente lacustre raso de baixa energia, influenciado por influxos esporádicos de areias oriundos de rios efêmeros (Talbot e Allen, 1996). Os influxos gerados por inundações relâmpagos formaram lobos sigmoidais com alta taxa de material em suspensão. A estruturação complexa de lobos sigmoidais (Figura 4C) está relacionada com barras de desembocadura proximais em bacias com baixa inclinação e lâmina d'água rasa (Postma, 1990). A deposição contínua e o soterramento progressivo das areias geraram processos de liquefação, originando acamamento maciço (Am), ao passo que a alternância dos processos de tração e suspensão levaram à deposição de ritmitos arenito/pelito (Rap). O espessamento ascendente das camadas arenosas no topo da sucessão sugere o aumento do influxo de areia para dentro do lago, cuja transição para depósitos não lacustres é representada por arenitos finos com laminação cruzada cavalgante supercrítica, laminação plana com truncamentos de baixo ângulo e acamamento flaser/wavy (Al; Figura 5A), originadas pela ação de ondas e correntes ao longo da borda do lago (Bridge e Demicco, 2008). Os depósitos com deformação dúctil (Figura 5B) e brechados experimentaram deformação sinsedimentar ligados a eventos de intensa compressão ou compactação (Figuras 5C e 5D).

O sistema lacustre da Formação Motuca foi, provavelmente, influenciado por períodos de contração e expansão (Figura 6), devido às variações das condições climáticas predominantemente áridas do final do Permiano e início do Triássico (Scotese et al., 1999; Golonka e Ford, 2000). Os mais expressivos períodos de contração ocorreram na 


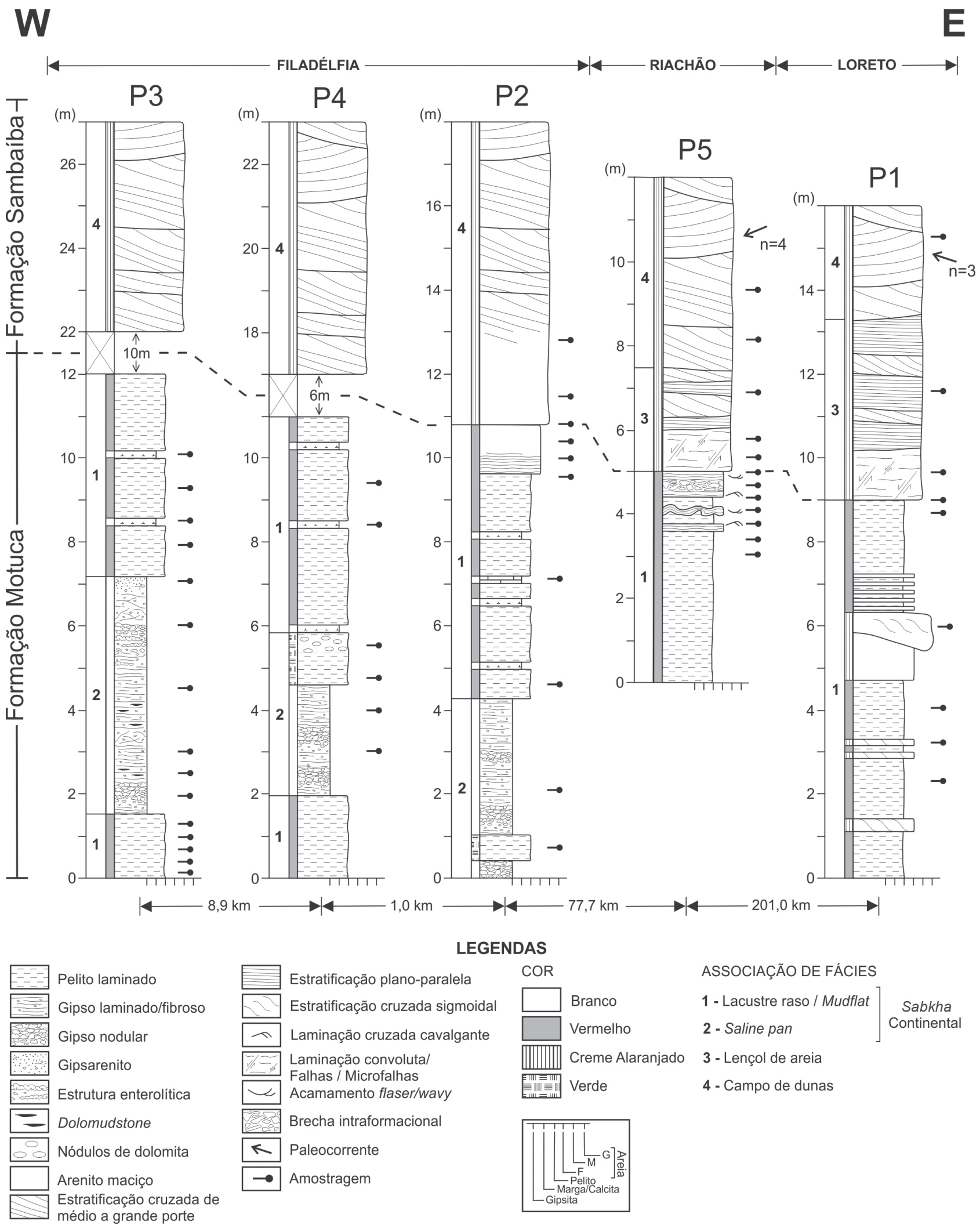

Figura 2. Perfis litoestratigráficos das formações Motuca e Sambaíba na região de Filadélfia (TO), Riachão (MA) e Loreto (MA). 


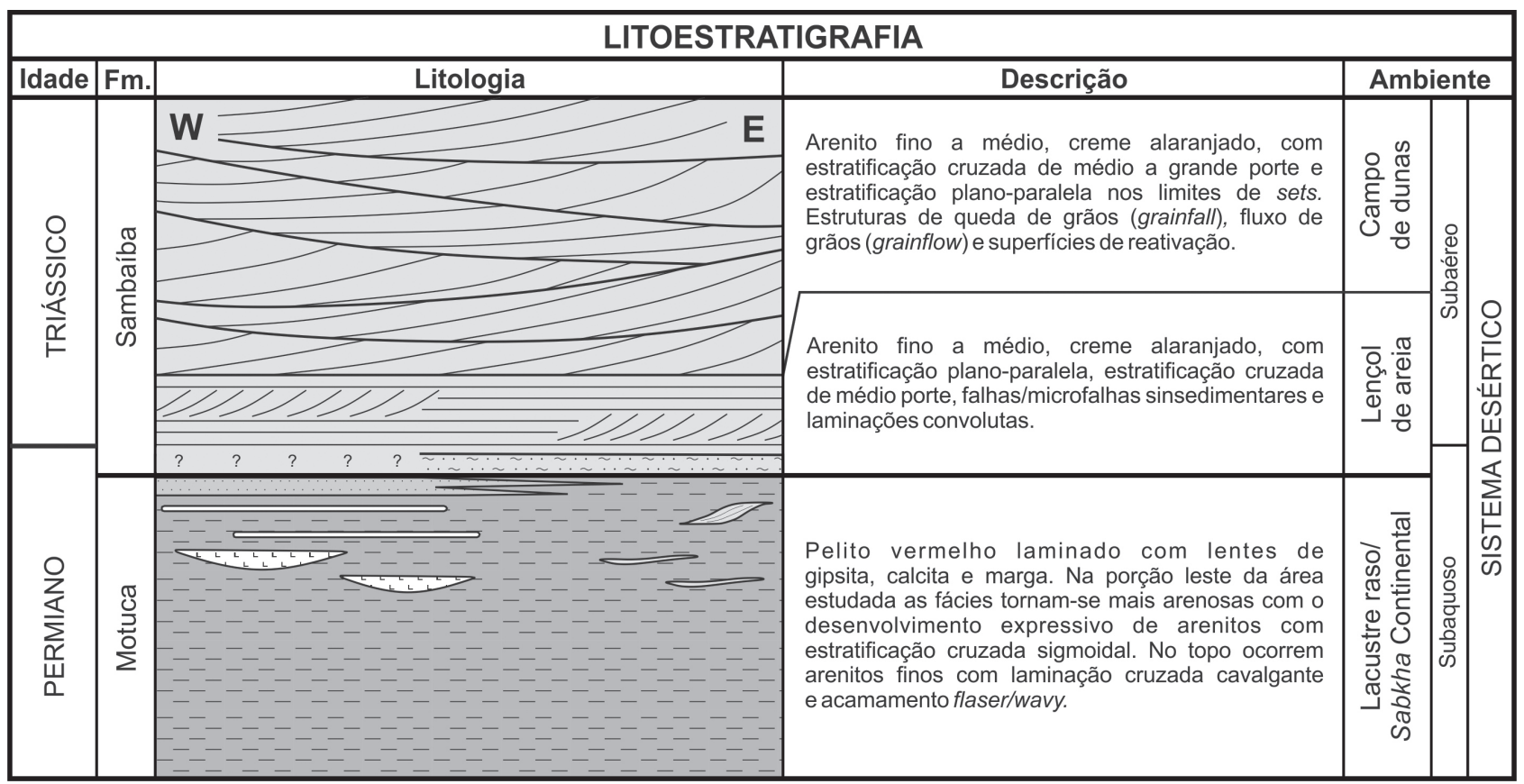

Figura 3. Litoestratigrafia das formações Motuca e Sambaíba na região de Filadélfia (TO), Riachão (MA) e Loreto (MA).

porção oeste da Bacia do Parnaíba, representados pelo desenvolvimento de mudflats associadas a lagoas efêmeras saturadas em carbonatos (Cf2) e a saline pans (AF2). A contração dos lagos ocorre quando o input de água é menor que a taxa de evaporação, individualizando lagoas supersaturadas rodeadas por mudflats (Salvany, 1997). A interação entre precipitação química de carbonatos e influxo de água superficial enriquecida em sedimentos finos é responsável pela formação de margas nas lagoas salinas (Schreiber e El Tabakh, 2000). A flutuação no nível da água e na salinidade originaram ciclos drying/brinning upward, caracterizados pela passagem de pelitos laminados de lagos rasos a margas e carbonatos maciços.

\section{Saline pan (AF2)}

Esta associação está diretamente relacionada com a AF1, sendo representada pelas fácies gipso nodular $(\mathrm{Gn})$, gipsolaminado $(\mathrm{Gl})$, gipsarenito $(\mathrm{Ga})$ e pelito laminado com nódulos de dolomita (Pln). As fácies evaporíticas consistem em corpos lenticulares de até $6 \mathrm{~m}$ de espessura e $100 \mathrm{~m}$ de comprimento (Figura 7), enquanto que a fácies siliciclástica/evaporítica (Pln) ocorre na forma de camadas tabulares métricas, lateralmente contínuas, sobrepostas aos evaporitos (Figura 8). Os evaporitos exibem lâminas horizontais contínuas (Gl; Figura 9A) de espessura milimétrica a centimétrica, onduladas, com alternância das cores branca (gipso fibroso/prismático) e cinza escuro (gipso em mosaico). Lentes milimétricas de dolomudstone são localmente observadas. Nódulos, estruturas chickenwire e enterolítica
(Gn; Figuras 7 e 9B), juntamente com gipsarenitos com laminação plana e marcas onduladas (Figuras 9C e 9D), configuram o topo de ciclos shallowing upward. Normalmente, na porção superior dos evaporitos ocorre pelito laminado esverdeado (Pln) com palygorskita e nódulos de dolomita.

A AF2 representa um subambiente com predomínio de processos de evaporação, alternados com influxos de água superficial e oscilações no nível freático durante os períodos de contração dos lagos (Salvany, 1997; Figura 6). Durante essa fase, ocorre à precipitação química de sulfato em ambiente subaquoso raso, originando cristais de gipsita fibrosa/prismática e em mosaico. O gipso fibroso/prismático cresce perpendicularmente ao substrato em contato com a salmoura (swallow-tail twinned), originando grass-like crusts (Kendall e Harwood, 1996). Esses cristais aumentam de tamanho e passam gradativamente para gipsita em mosaico, formada pelo crescimento displacivo em condições bastante rasas ou na zona freática capilar, implicando períodos de rebaixamento do nível da salmoura e eventuais exposições subaéreas (Warren, 2006). Exposições prolongadas proporcionam o crescimento e a coalescência de nódulos de gipsita dentro das camadas de pelitos, originando estruturas chickenwire e enterolítica (Boggs, 2009). Além disso, a exposição resulta no fraturamento do gipso devido à dissecação, originando grãos que são retrabalhados por correntes trativas unidirecionais e atividade de ondas, algumas vezes desenvolvendo marcas onduladas (Schreiber e El Tabakh, 2000). Influxos de águas menos salinas dissolvem a parte superior das crostas de gipsita precipitadas previamente e, posteriormente, depositam 
Tabela 1. Fácies, associação de fácies e processos sedimentares da Formação Motuca.

\begin{tabular}{|c|c|c|c|c|}
\hline $\mathrm{Fm}$. & Fácies & Descrição & Processos & $\begin{array}{l}\text { Associação } \\
\text { de fácies }\end{array}$ \\
\hline \multirow{11}{*}{ 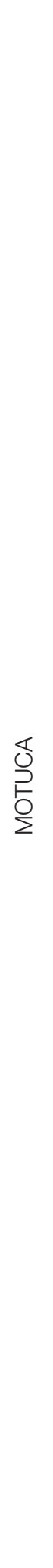 } & $\begin{array}{l}\text { Arenito com } \\
\text { laminação cruzada } \\
\text { cavalgante (Al) }\end{array}$ & $\begin{array}{l}\text { Arenito fino de coloração avermelhada com } \\
\text { laminação cruzada cavalgante supercrítica, } \\
\text { truncamento de baixo ângulo, acamamento } \\
\text { flaser/wavy, convoluções e brecha associada. }\end{array}$ & $\begin{array}{l}\text { Migração de marcas onduladas } \\
\text { em ambiente subaquoso com } \\
\text { alta taxa de sedimentos em } \\
\text { suspensão. Processos de } \\
\text { liquefação. }\end{array}$ & \multirow{7}{*}{ 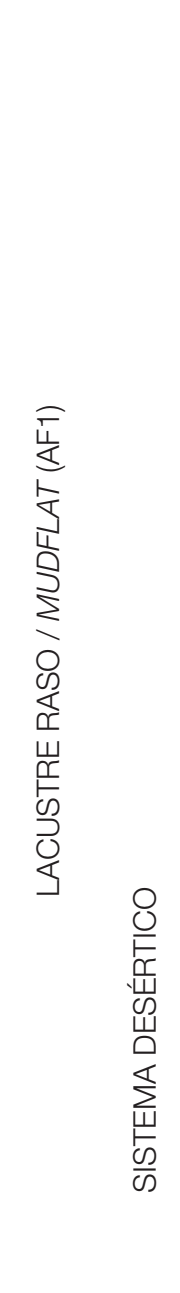 } \\
\hline & $\begin{array}{l}\text { Arenito com } \\
\text { estratificação } \\
\text { cruzada sigmoidal } \\
\text { (Asg) }\end{array}$ & $\begin{array}{c}\text { Camadas lenticulares de arenito médio a } \\
\text { grosso de coloração avermelhada com } \\
\text { estratificação cruzada sigmoidal. Apresenta } \\
\text { grãos moderadamente selecionados, } \\
\text { subangulosos a arredondados com alta } \\
\text { esfericidade. Os sets variam de 0,1 a 0,3 m de } \\
\text { espessura e são lateralmente contínuos por } \\
\text { até } 12 \text { m. }\end{array}$ & $\begin{array}{l}\text { Desaceleração do fluxo sobre } \\
\text { uma bacia de baixa energia, } \\
\text { formando feições lobadas. }\end{array}$ & \\
\hline & Arenito maciço (Am) & $\begin{array}{c}\text { Camadas tabulares decimétricas a métricas } \\
\text { de arenito fino maciço de coloração rosada. } \\
\text { Possui grãos moderadamente selecionados, } \\
\text { subangulosos a arredondados em matriz } \\
\text { pelítica. }\end{array}$ & $\begin{array}{l}\text { Deposição contínua de } \\
\text { sedimentos, posteriormente } \\
\text { modificada por processos de } \\
\text { liquefação. }\end{array}$ & \\
\hline & $\begin{array}{l}\text { Ritmito arenito/pelito } \\
\text { (Rap) }\end{array}$ & $\begin{array}{c}\text { Camadas tabulares com intercalações } \\
\text { milimétricas a centimétricas de arenitos finos e } \\
\text { pelitos. }\end{array}$ & $\begin{array}{l}\text { Alternância rítmica de } \\
\text { suspensão e tração em } \\
\text { ambiente de baixa energia. }\end{array}$ & \\
\hline & Pelito laminado (PI) & $\begin{array}{l}\text { Camadas tabulares métricas, lateralmente } \\
\text { contínuas, de pelito vermelho laminado. }\end{array}$ & $\begin{array}{l}\text { Deposição por suspensão em } \\
\text { ambiente de baixa energia, } \\
\text { com influxos esporádicos de } \\
\text { areias. }\end{array}$ & \\
\hline & Marga maciça (Mm) & $\begin{array}{c}\text { Camadas tabulares centimétricas e } \\
\text { lateralmente contínuas de marga maciça } \\
\text { esbranquiçada. }\end{array}$ & $\begin{array}{l}\text { Precipitação química de } \mathrm{CaCO}_{3} \\
\text { associada com influxo contínuo } \\
\text { de siliciclásticos. }\end{array}$ & \\
\hline & $\begin{array}{l}\text { Calcário maciço } \\
\text { (Cm) }\end{array}$ & $\begin{array}{c}\text { Camadas tabulares centimétricas e } \\
\text { lateralmente contínuas de calcita maciça } \\
\text { avermelhada. }\end{array}$ & $\begin{array}{l}\text { Precipitação química de } \\
\qquad \mathrm{CaCO}_{3} .\end{array}$ & \\
\hline & $\begin{array}{l}\text { Pelito laminado com } \\
\text { nódulos de dolomita } \\
\text { (PIn) }\end{array}$ & $\begin{array}{c}\text { Camadas tabulares de até } 1 \mathrm{~m} \text { de espessura } \\
\text { de pelito verde laminado com palygorskita e } \\
\text { nódulos de dolomita. }\end{array}$ & $\begin{array}{l}\text { Deposição por suspensão em } \\
\text { ambiente de baixa energia sob } \\
\text { condições climáticas áridas a } \\
\text { semiáridas com alta taxa de } \\
\text { evaporação. }\end{array}$ & \multirow{4}{*}{ 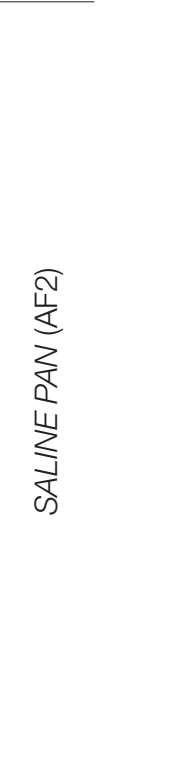 } \\
\hline & Gipso nodular (Gn) & $\begin{array}{c}\text { Gipso de coloração branca, formado por } \\
\text { nódulos irregulares limitados parcialmente } \\
\text { ou completamente por gipso fibroso, pelito } \\
\text { e/ou carbonato. Estruturas chickenwire e } \\
\text { enterolítica. }\end{array}$ & $\begin{array}{l}\text { Crescimento e coalescência de } \\
\text { nódulos evaporíticos em poros } \\
\text { contendo água supersaturada } \\
\text { em sulfato na zona capilar. }\end{array}$ & \\
\hline & Gipso laminado (GI) & $\begin{array}{l}\text { Gipso formado por lâminas horizontais } \\
\text { lateralmente contínuas, milimétricas a } \\
\text { centimétricas, onduladas, com alternância das } \\
\text { cores branca (gipso fibroso/prismático) e cinza } \\
\text { escuro (gipso em mosaico). Lentes milimétricas } \\
\text { de dolomudstone. }\end{array}$ & $\begin{array}{l}\text { Precipitação química de sulfato } \\
\text { em ambiente subaquoso } \\
\text { influenciado por variações } \\
\text { sazonais na profundidade da } \\
\text { salmoura. }\end{array}$ & \\
\hline & Gipsarenito (Ga) & $\begin{array}{l}\text { Gipso formado por grãos de gipso. Apresenta } \\
\text { laminação plana e marcas onduladas. }\end{array}$ & $\begin{array}{l}\text { Acumulações clásticas de } \\
\text { evaporito influenciadas por } \\
\text { ondas e/ou correntes. }\end{array}$ & \\
\hline
\end{tabular}


Tabela 2. Fácies, associação de fácies e processos sedimentares da Formação Sambaíba.

\begin{tabular}{|c|c|c|c|c|c|}
\hline $\mathrm{Fm}$. & Fácies & Descrição & Processos & $\begin{array}{r}\text { Assc } \\
\text { de }\end{array}$ & $\begin{array}{l}\text { ação } \\
\text { cies }\end{array}$ \\
\hline 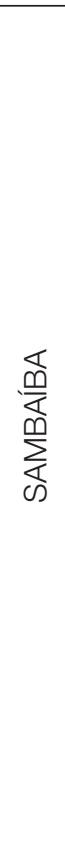 & $\begin{array}{c}\text { Arenito com } \\
\text { estratificação } \\
\text { cruzada de médio a } \\
\text { grande porte (Acz) }\end{array}$ & $\begin{array}{c}\text { Arenito fino a médio de coloração creme } \\
\text { alaranjada com estratificação cruzada de médio } \\
\text { a grande porte. Os sets possuem espessuras } \\
\text { que variam de 0,3 a } 16 \text { m e migração preferencial } \\
\text { para NW-SW. Grãos bem selecionados, } \\
\text { bimodais, bem arredondados com alta } \\
\text { esfericidade. Estruturas de grainfall, grainflow e } \\
\text { superfícies de reativação. } \\
\text { Camadas decimétricas a métricas de arenito } \\
\text { fino a médio de coloração creme alaranjada com } \\
\text { estratificação plano-paralela e laminação cruzada } \\
\text { de baixo ângulo. } \\
\text { Arenito fino a médio de coloração creme } \\
\text { esbranquiçado com laminação convoluta, falhas } \\
\text { e microfalhas. As falhas/microfalhas mostram } \\
\text { planos de baixo e alto ângulo, curvados } \\
\text { e crenulados, com deslocamentos sub- } \\
\text { horizontais, normais e oblíquos com mergulho } \\
\text { preferencial para NW-SE e W-E. Espaços } \\
\text { nas curvaturas dos planos são geralmente } \\
\text { preenchidos por material argiloso. }\end{array}$ & $\begin{array}{l}\text { Migração de formas de } \\
\text { leito planas a levemente } \\
\text { onduladas (wind ripples) } \\
\text { relacionada a alta velocidade } \\
\text { do vento. }\end{array}$ & 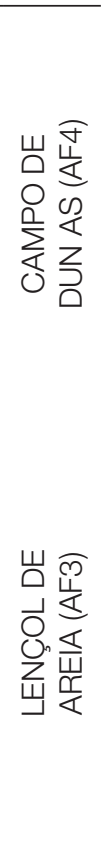 & 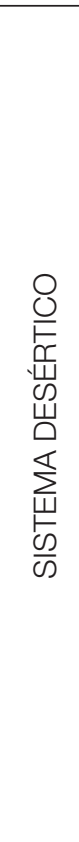 \\
\hline
\end{tabular}

sw
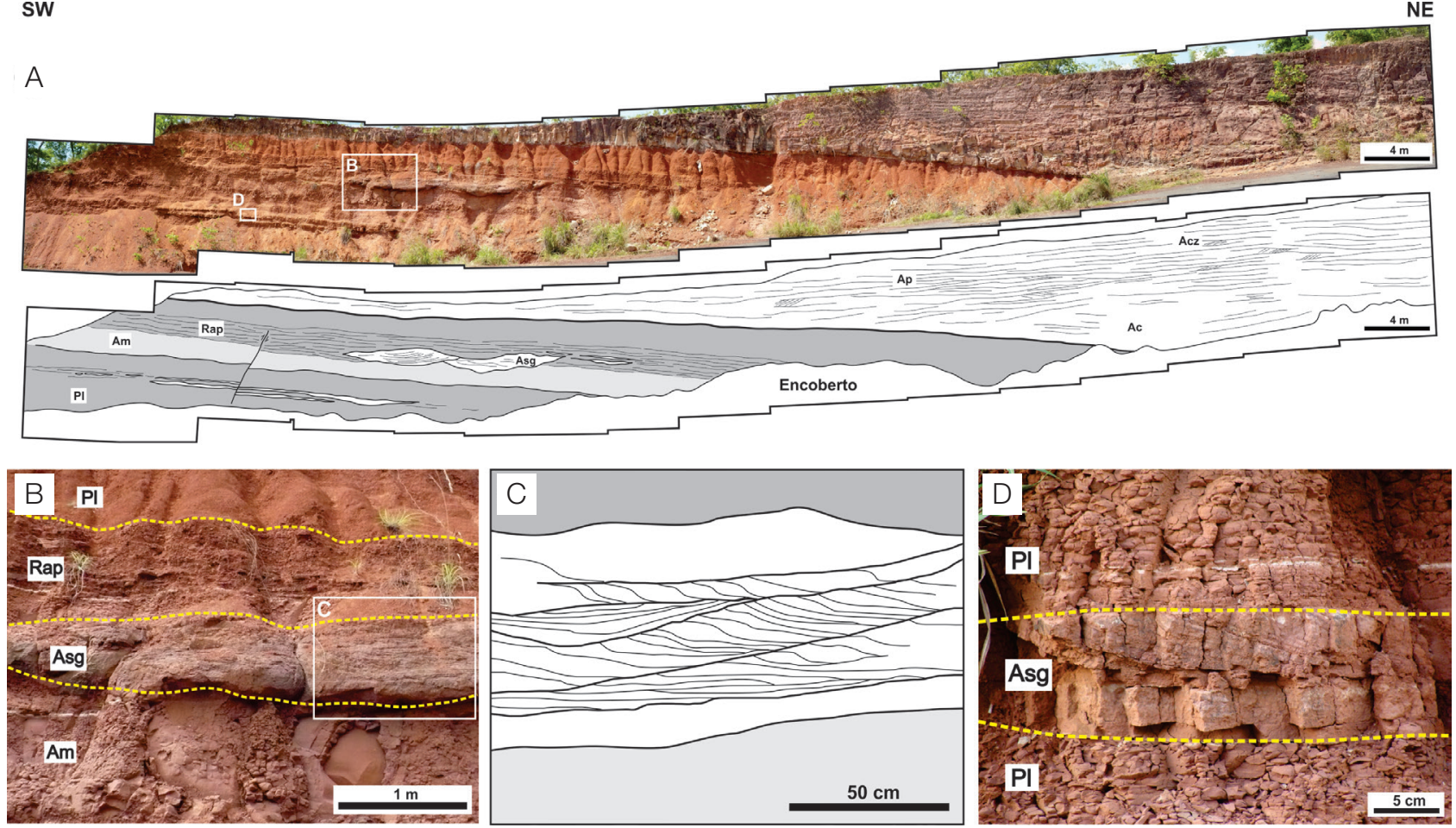

Figura 4. Contato litoestratigráfico entre as formações Motuca e Sambaíba (Perfil P1). (A) Passagem de pelitos laminados (PI) e ritmitos (Rap) com arenitos sigmoidais (Asg) da Formação Motuca para os arenitos da Formação Sambaíba. (B) Relação entre as fácies do conjunto de fácies 1 na porção superior da Formação Motuca. (C) Detalhe da fácies Asg. Note a estruturação complexa do lobo sigmoidal. (D) Fácies Asg concordante ao pelito (Pl). 

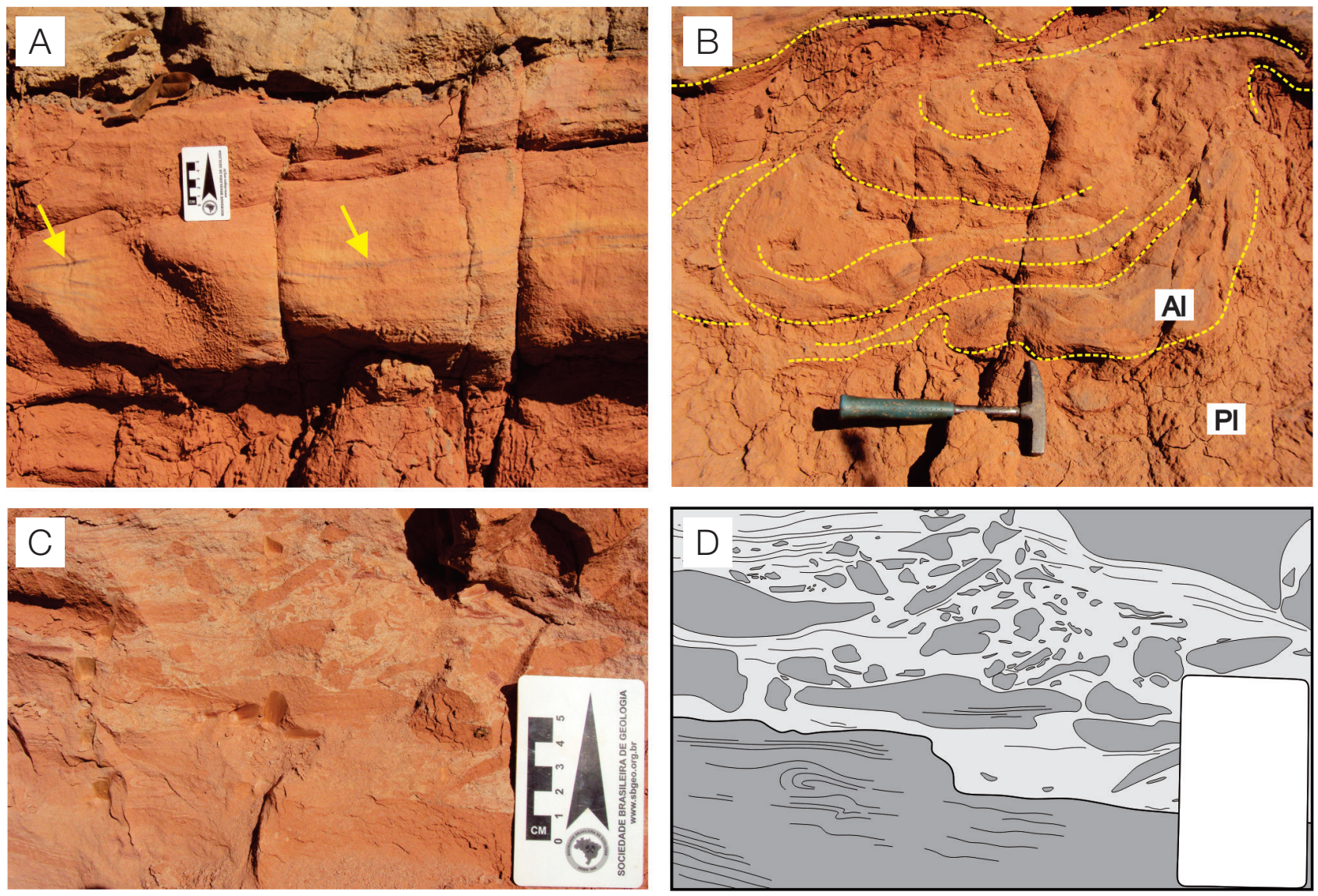

Figura 5. Fácies e deformações do topo da Formação Motuca (Perfil P5). (A) Arenito laminado (fácies Al) apresentando acamamento flaser/wavy, com destaque para os níveis mais argilosos (setas amarelas). (B) Deformação dúctil nas fácies Al e PI. (C) e (D) Brecha com clastos tabulares.

dolomudstone (Kendall e Harwood, 1996). A elevada taxa de evaporação condicionada pelo clima árido a semiárido e a grande disponibilidade de $\mathrm{Mg}$ nos lagos favorecem a formação de palygorskita e dolomita (Velde, 1985; Jones e Galan, 1988; Tlili et al., 2010). A palygorskita provavelmente foi precipitada diretamente nas soluções aquosas, enquanto os nódulos de dolomita se formaram logo abaixo da interface água-sedimento ao longo de horizontes contínuos durante a eodiagênese, refletindo o nível de supersaturação que as águas intersticiais alcançaram (Tucker, 1991).

\section{Associações de fácies da Formação Sambaíba}

\section{Lençol de areia (AF3)}

A AF3 consiste nas fácies arenito com laminação convoluta, falhas e microfalhas (Ac), arenito com estratificação plano-paralela (Ap) e arenito com estratificação cruzada de médio porte (Acz). Esta associação representa a base da Formação Sambaíba, compreendendo uma sucessão de até $5 \mathrm{~m}$ de espessura e lateralmente contínua por pelo menos $200 \mathrm{~km}$. O contato direto com a Formação Motuca é marcado pelos arenitos da fácies Ac, cujas falhas/microfalhas mostram planos de baixo e alto ângulo, curvados e crenulados, com deslocamentos sub-horizontais, normais e oblíquos, com direção preferencial para NW-SE e W-E (Figuras 10A a 10C). Em algumas porções, as falhas possuem preenchimento argiloso. Os estratos com estratificação plano-paralela e laminação cruzada de baixo ângulo da fácies Ap são dominantes nesta associação, apresentando subordinadamente estratificação cruzada de médio porte (fácies Acz; Figuras 4A e 10D).

Esta associação foi depositada em planícies arenosas extensas, localmente com áreas úmidas, intensamente retrabalhadas por processos eólicos (Wilson, 1971; Mountney, 2006). Os lençóis de areia margeiam campos de dunas, sendo caracterizados pela migração de wind ripples (fácies Ap) e dunas eólicas de porte reduzido (fácies Acz) que são constantemente modificadas pelo leito plano (Brookfield, 1977; Kocurek e Havholm, 1993). 


\section{ESTÁGIO DE EXPANSÃO LACUSTRE}

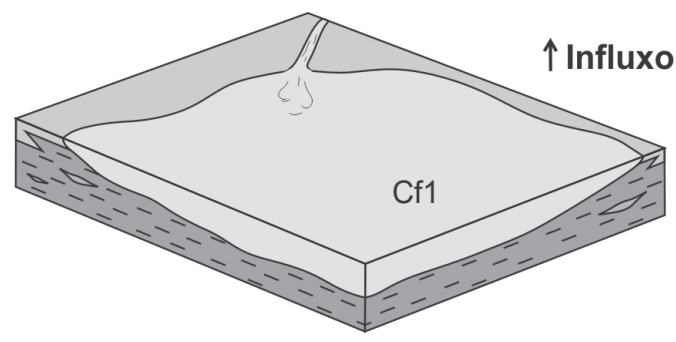

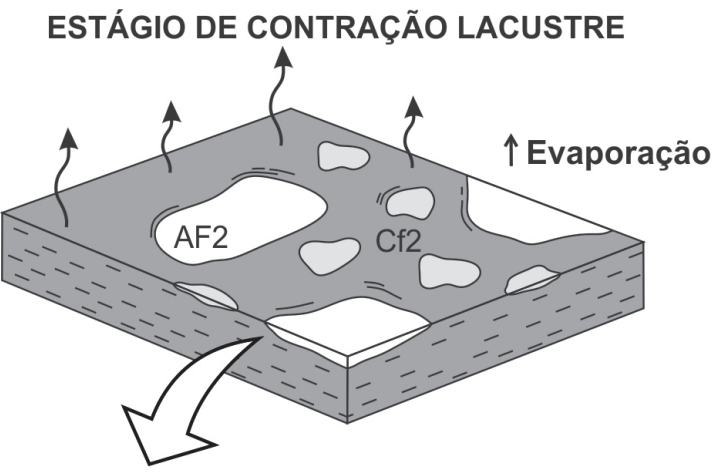

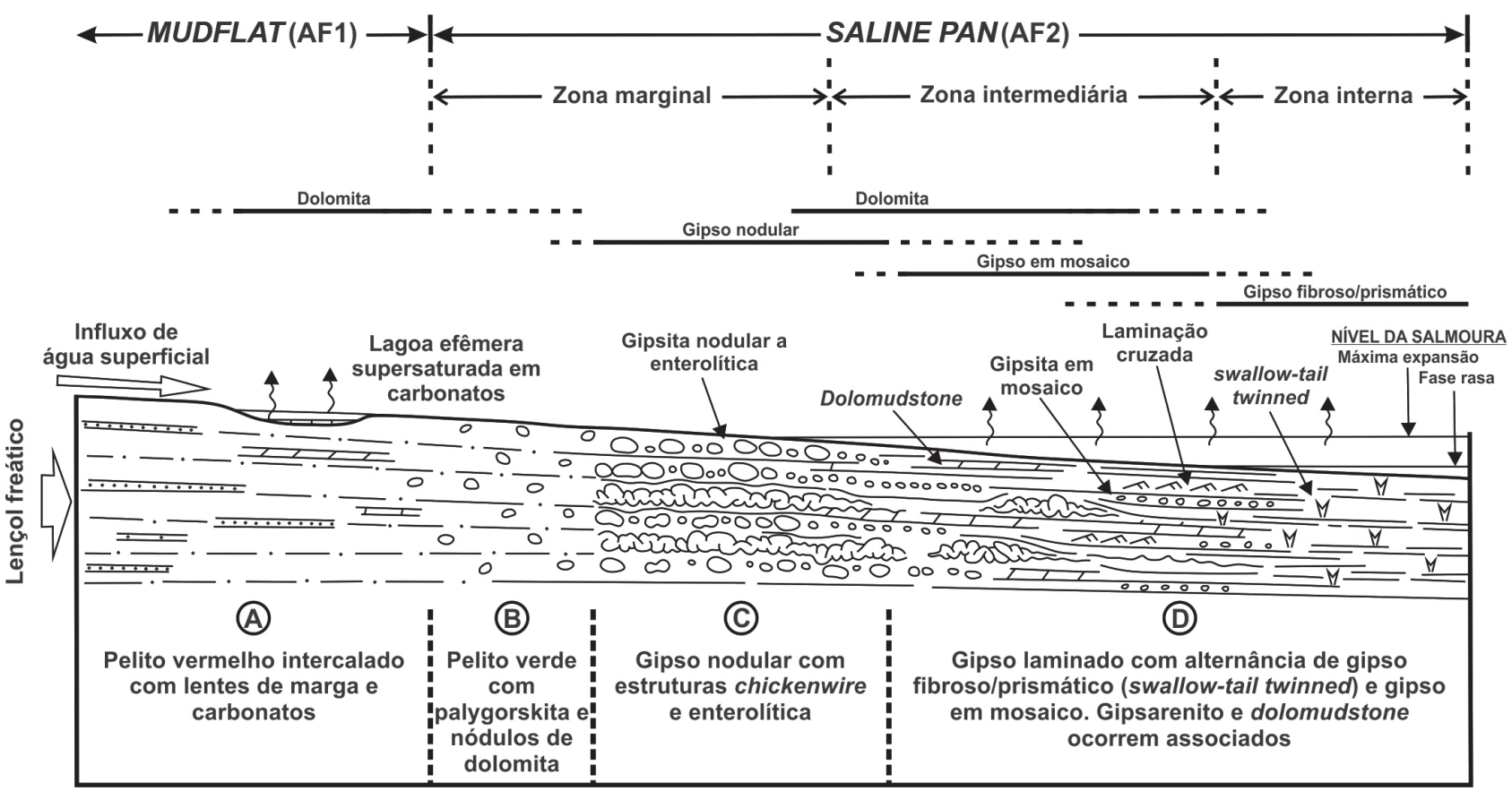

Figura 6. Modelo esquemático de um sistema lacustre influenciado por períodos de contração e expansão, com destaque para seção transversal de depósitos de saline pans e mudflats (Adaptado de Salvany, 1997). O período de expansão é marcado pelo aumento do influxo para o lago e deposição contínua de pelitos (Cf1), ao passo que o período de contração ocorre em momentos de elevada taxa de evaporação, originando lagoas efêmeras supersaturadas em carbonatos, mudflats (Cf2) e saline pans (AF2).

Intervalos deformados lateralmente contínuos por centenas de quilômetros ocorrem na zona de contato entre as formações Motuca e Sambaíba. A ocorrência conjunta de pelitos com camadas contorcidas (Figura 5B) e brechadas (Figuras 5C e 5D) (Formação Motuca), arenitos com falhas/microfalhas sinsedimentares, laminação convoluta e diques de injeção preenchidos por argilitos (Formação Sambaíba) são interpretados como sismitos induzidos por terremotos de alta magnitude ( $>8$ na escala Richter; Rodríguez-Pascua et al., 2000). A injeção do material argiloso nos planos de falhas ocorreu devido à contração/dilatação de camadas juntamente com processos de liquefação desencadeados pelos sismos, relacionando-se também ao enraizamento das falhas a camadas pelíticas basais saturadas em água (RodríguezPascua et al., 2000).

\section{Campo de dunas (AF4)}

Os depósitos da AF4 englobam as camadas tabulares de arenitos finos a médios expostos na forma de mesetas sedimentares ao longo de praticamente toda a área estudada, representando uma sucessão de pelo menos $400 \mathrm{~m}$ de espessura (Figuras 11A e 11B). São representados principalmente pelas fácies arenito com estratificação cruzada de médio a grande porte (Acz) e, subordinadamente, arenito com estratificação plano-paralela (Ap). A fácies Acz é formada por arenitos finos a médios, de coloração 

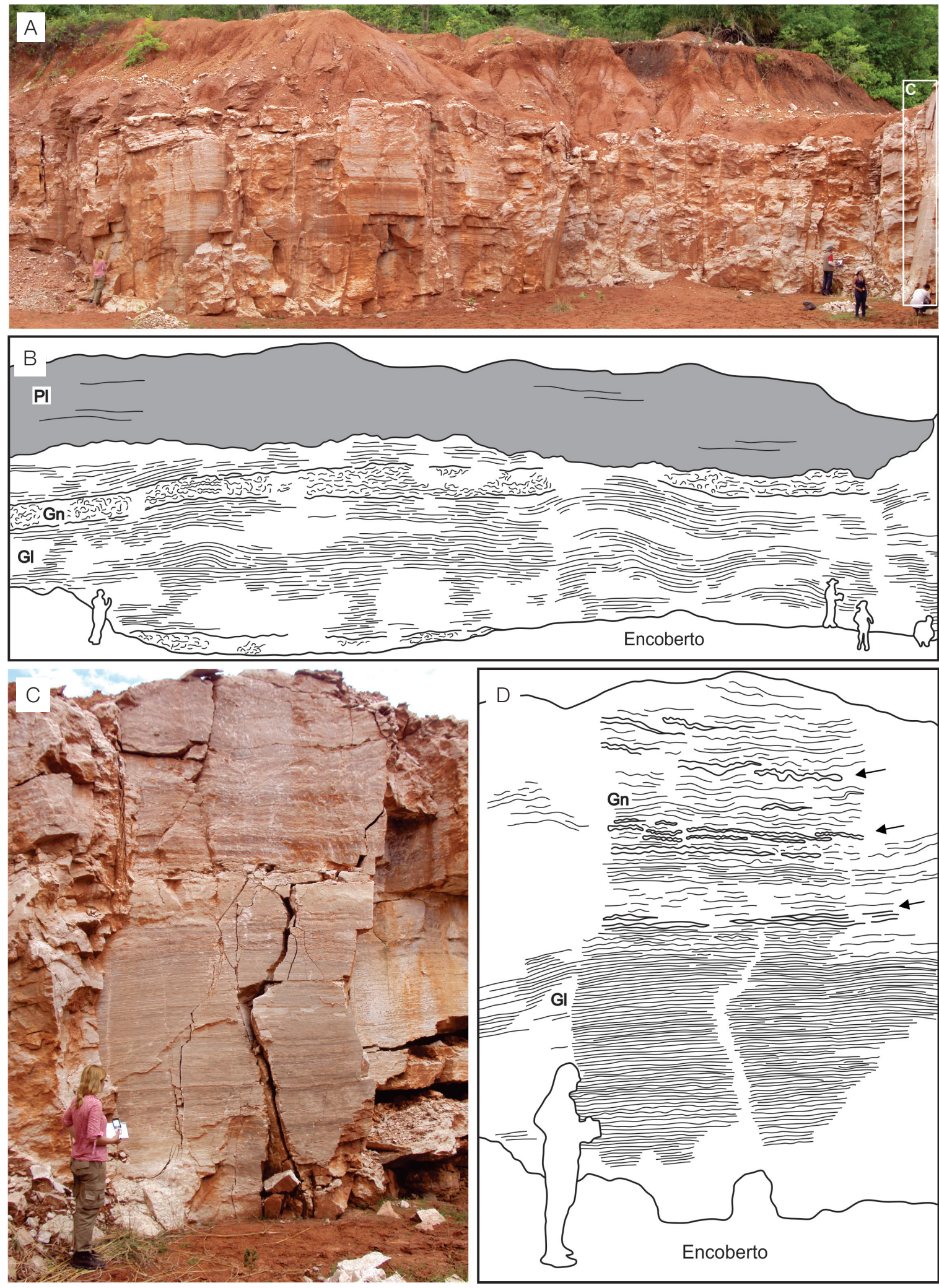

Figura 7. Aspectos faciológicos dos evaporitos da Formação Motuca no perfil P3. (A) e (B) Seção panorâmica da AF2, mostrando a relação entre as fácies gipso laminado e ondulado (GI), gipso nodular (Gn) e pelito laminado (PI). (C) e (D) Passagem gradual da fácies Gl para fácies Gn com estruturas enterolíticas (setas). 

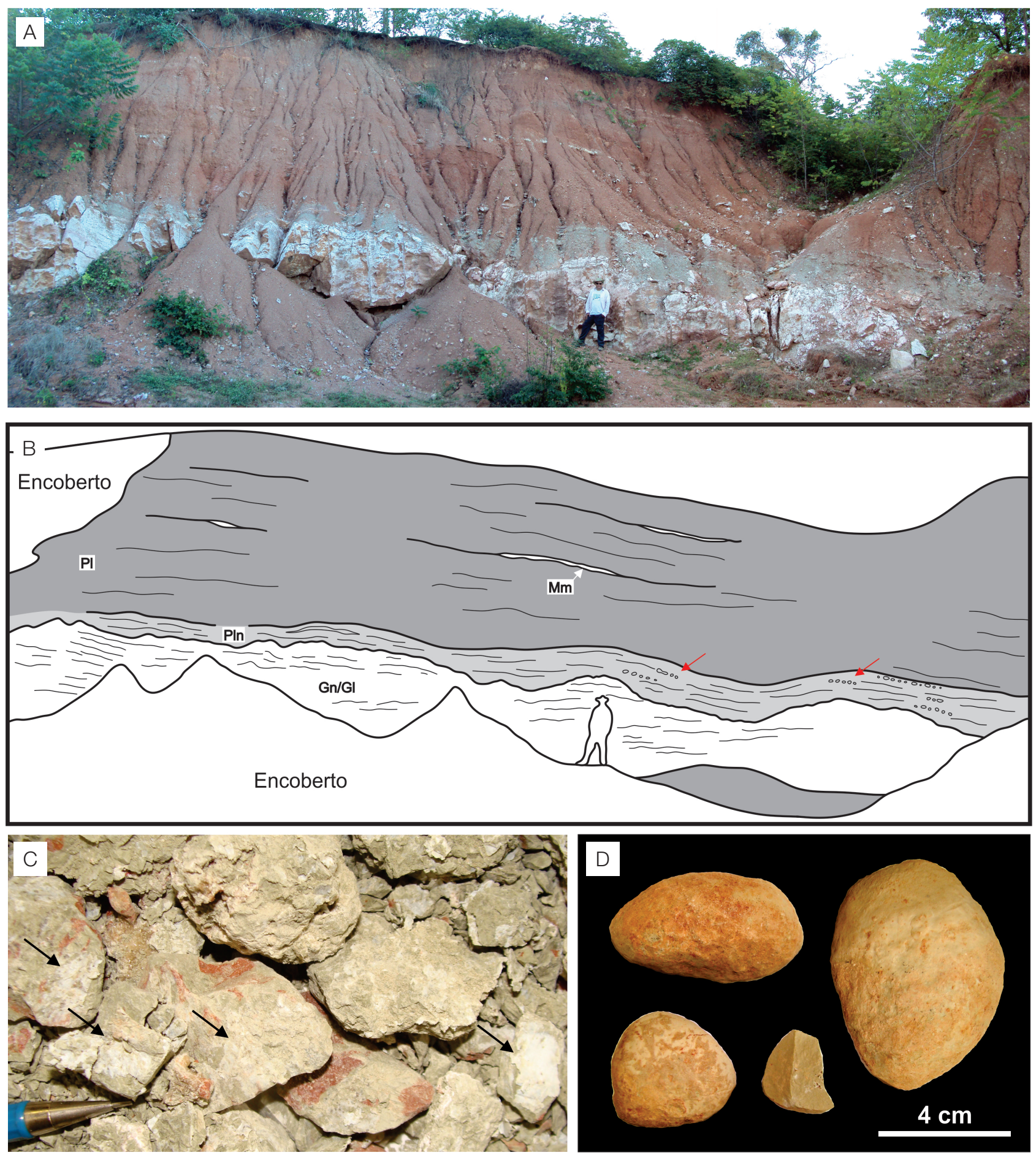

Figura 8. Aspectos estratigráficos dos evaporitos e pelitos da Formação Motuca no perfil P4. (A) e (B) Seção panorâmica mostrando a sobreposição da fácies PIn aos evaporitos (setas vermelhas: nódulos de dolomita). (C) Palygorskita (setas pretas) e (D) Nódulos de dolomita associados aos pelitos verdes da fácies Pln.

creme alaranjada, com estratificação cruzada de médio a grande porte (Figuras 11C a 11E). Apresenta grãos bem selecionados, bimodais, bem arredondados com alta esfericidade. Os sets possuem espessuras que variam de
0,3 a $16 \mathrm{~m}$, exibindo espessamento ascendente (coarsening upward) e migração preferencial para NW e SW. Superfícies de reativação, estruturas de queda de grãos (grainfall) e fluxo de grãos (grainflow) são observadas. 

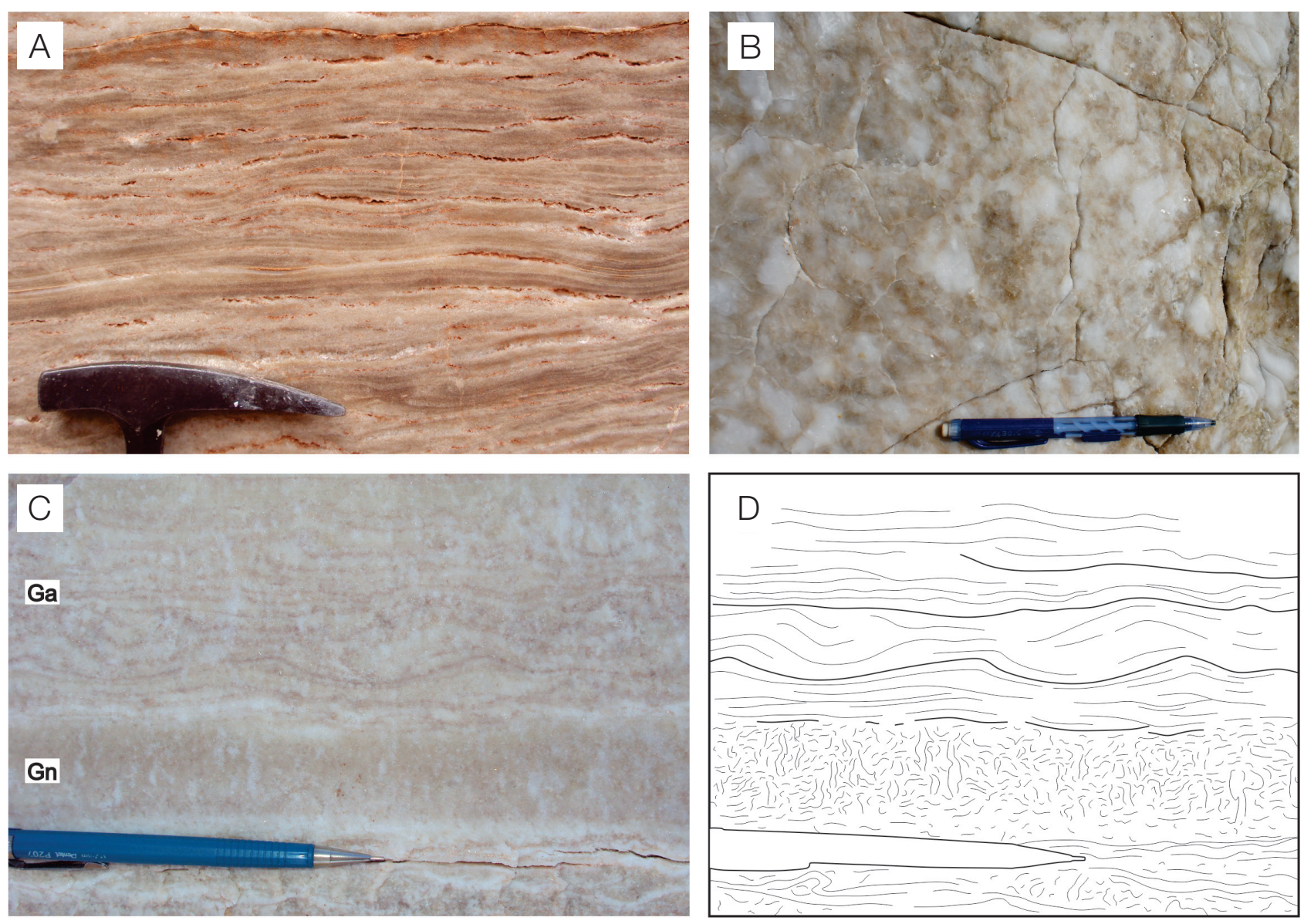

Figura 9. Características dos evaporitos da Formação Motuca. (A) Gipso com laminação ondulada e alternância das cores branca (gipso fibroso/prismático) e cinza escuro (gipso em mosaico). (B) Gipso nodular com estrutura chickenwire. (C) Foto e (D) Desenho esquemático de gipso nodular (Gn) gradando para gipsarenito (Ga) com laminação plana e marcas onduladas.

A fácies Ap ocorre de maneira restrita, sendo representada por estratos tabulares e lenticulares dispersos nos depósitos da fácies Acz.

A AF4 é interpretada como parte de um erg composto por dunas/draas em zona saturada em areia, com interdunas secas subordinadas (Wilson, 1971; Fryberger et al., 1979). As zonas saturadas são caracterizadas pela cobertura total de areia, proporcionando o sucessivo cavalgamento de dunas/draas e interdunas secas. As dunas eólicas migram a partir de processos trativos (wind ripples) e gravitacionais de grainflow e grainfall responsáveis pelo desmoronamento na face frontal da duna (slipface), originando estratos cruzados internos (fácies Acz). Os estratos planos de interdunas originam-se pela migração de wind ripples nas depressões entre dunas eólicas ou draas, gerando estratos cavalgantes transladantes subcríticos. A pequena expressão desses depósitos de interdunas associada à quantidade de estratos cruzados possibilita classificá-las como interdunas deflacionárias, cujos sedimentos são constantemente remobilizados e disponibilizados para a construção de dunas eólicas (Ahlbrandt e Fryberger, 1981).

\section{MODELO DEPOSICIONAL}

A análise faciológica e estratigráfica dos depósitos das regiões de Filadélfia (TO), Riachão (MA) e Loreto (MA) permitiram reconhecer quatro associações de fácies relacionadas a um sistema desértico (Figura 3), estando representadas pela passagem de depósitos lacustres rasos com mudflats e saline pans da Formação Motuca, para depósitos eólicos de lençol de areia e de campo de dunas da Formação Sambaíba (Figura 12).

O início da sedimentação Motuca é marcado pela deposição de espessas camadas de pelitos laminados em um extenso ambiente lacustre raso de baixa energia (AF1), influenciado esporadicamente por influxos de areias oriundas de rios efêmeros (Figura 12A). Essa sedimentação em clima árido sugere que o nível de base estratigráfico (nível freático) encontrava-se 

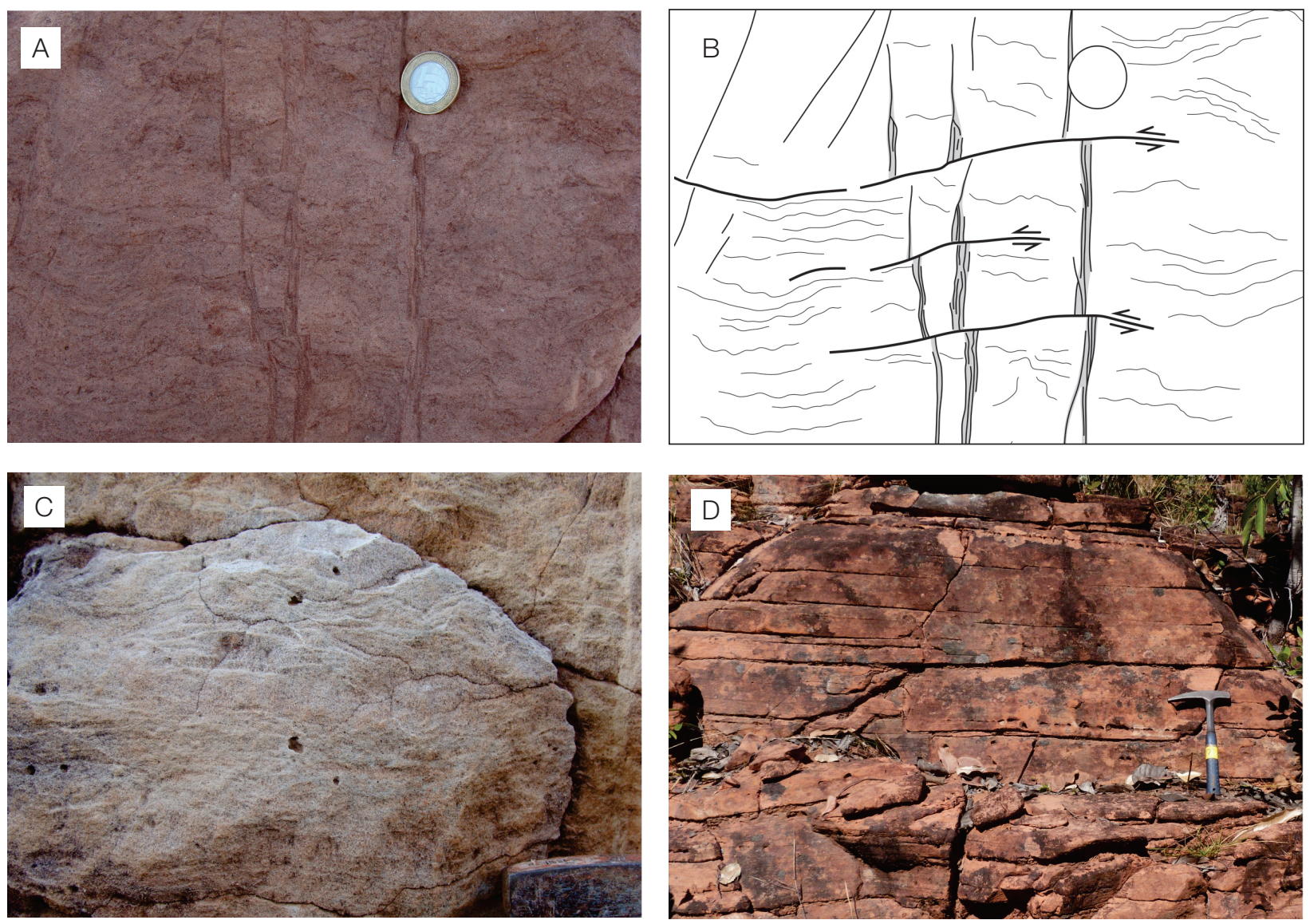

Figura 10. Estruturas observadas nos arenitos da base da Formação Sambaíba. (A) e (B) Arenito com laminação convoluta e microfalhas com deslocamentos sub-horizontais, normais e oblíquos de alto ângulo. (C) Detalhe da laminação convoluta. (D) Arenito com estratificação plano-paralela.

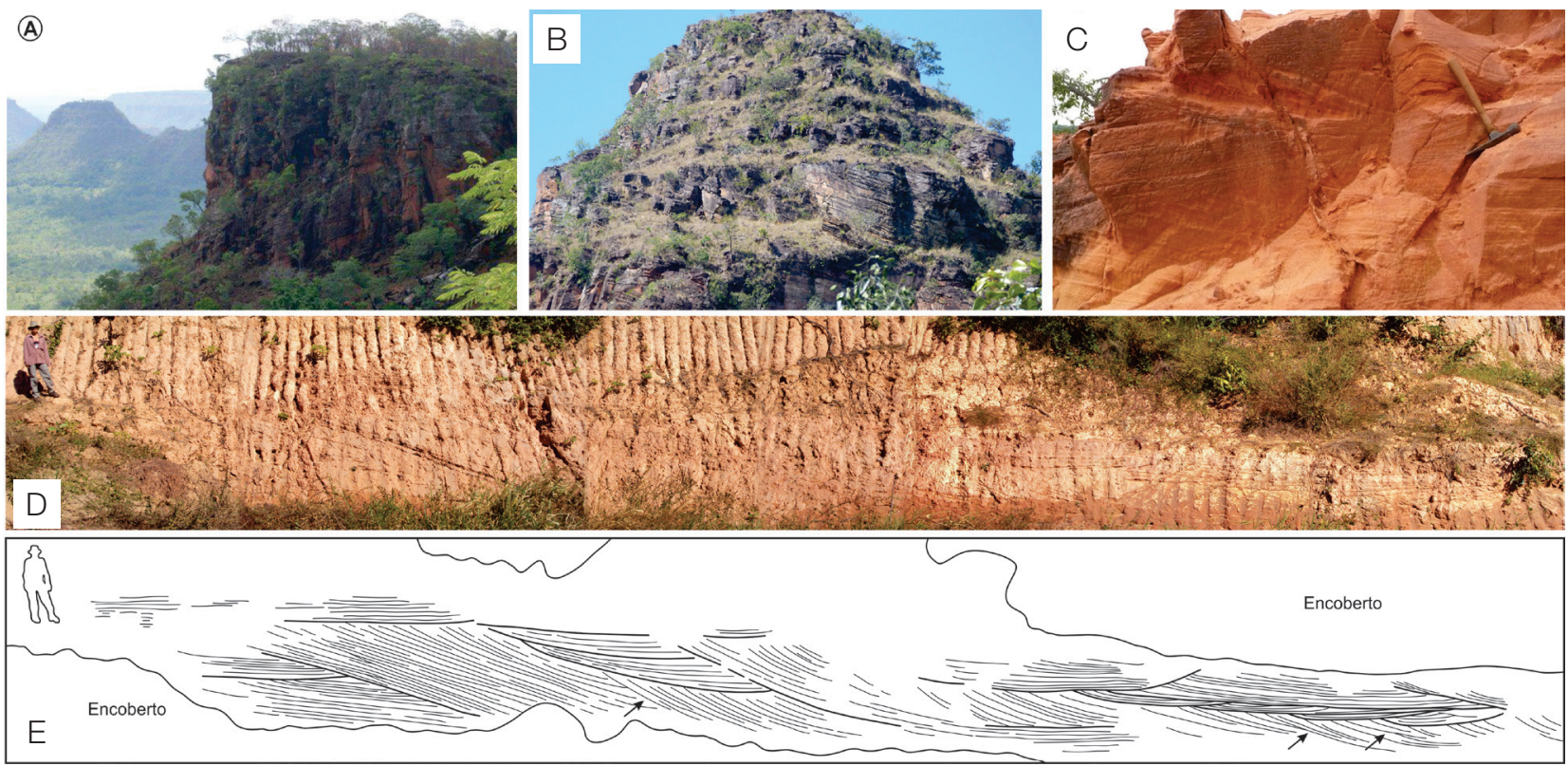

Figura 11. Aspectos morfológicos e litológicos da Formação Sambaíba. (A) Camadas tabulares de arenitos da Formação Sambaíba expostos na forma de mesetas sedimentares na região de Filadélfia (TO). (B) Detalhe das mesetas mostrando diversos sets de estratificação cruzada de grande porte em sistemas eólicos secos. (C) Truncamentos dos sets de estratificação cruzada. (D) e (E) Inúmeros sets de estratificação cruzada com superfícies de reativação (setas). 
relativamente elevado, com a predominância de subsidência local. No entanto, regionalmente ocorria o soerguimento da porção setentrional da Plataforma SulAmericana resultante da colisão entre os continentes Gondwana e Laurásia (Orogenia Allegheniana) durante o Neopermiano/Eotriássico (Zalán, 1991). Essa compressão generalizada ao norte de Gondwana foi capaz de gerar deflexões locais na sinéclise, possibilitando a acumulação de sedimentos na Bacia do Parnaíba, e soerguimentos expressivos nas Bacias do Solimões e do Amazonas, originando discordâncias erosivas regionais que se estendem até a Bacia do Paraná (Cunha et al., 2007). O contínuo soerguimento a noroeste da Bacia do Parnaíba refletiu no deslocamento do depocentro da Bacia para leste e na redução do nível de base estratigráfico, levando ao isolamento e à evaporação contínua de corpos aquosos na borda oeste da Bacia, ocasionando a precipitação de sulfatos em saline pans (AF2) envolvidas por mudflats (Figura 12B).

Esses depósitos são recobertos gradualmente por extensas planícies arenosas caracterizadas pela migração de wind ripples e dunas eólicas de porte reduzido (AF3), representando a porção marginal do deserto Sambaíba (Figura 12C). Após a implantação desse lençol de areia, a região estuda foi afetada por abalos sísmicos de intensa magnitude (Figura 12D). Essa interpretação é condizente, devido à continuidade por pelo menos $200 \mathrm{~km}$ de camadas apresentando acamamento convoluto e falhas/microfalhas sindeposicionais no mesmo nível estratigráfico na base da Formação Sambaíba, além de brechas e camadas dobradas sinsedimentares no topo da Formação Motuca na região de Riachão (MA).

Os depósitos de campos de dunas (AF4) são os mais abrangentes da Formação Sambaíba e marcam a
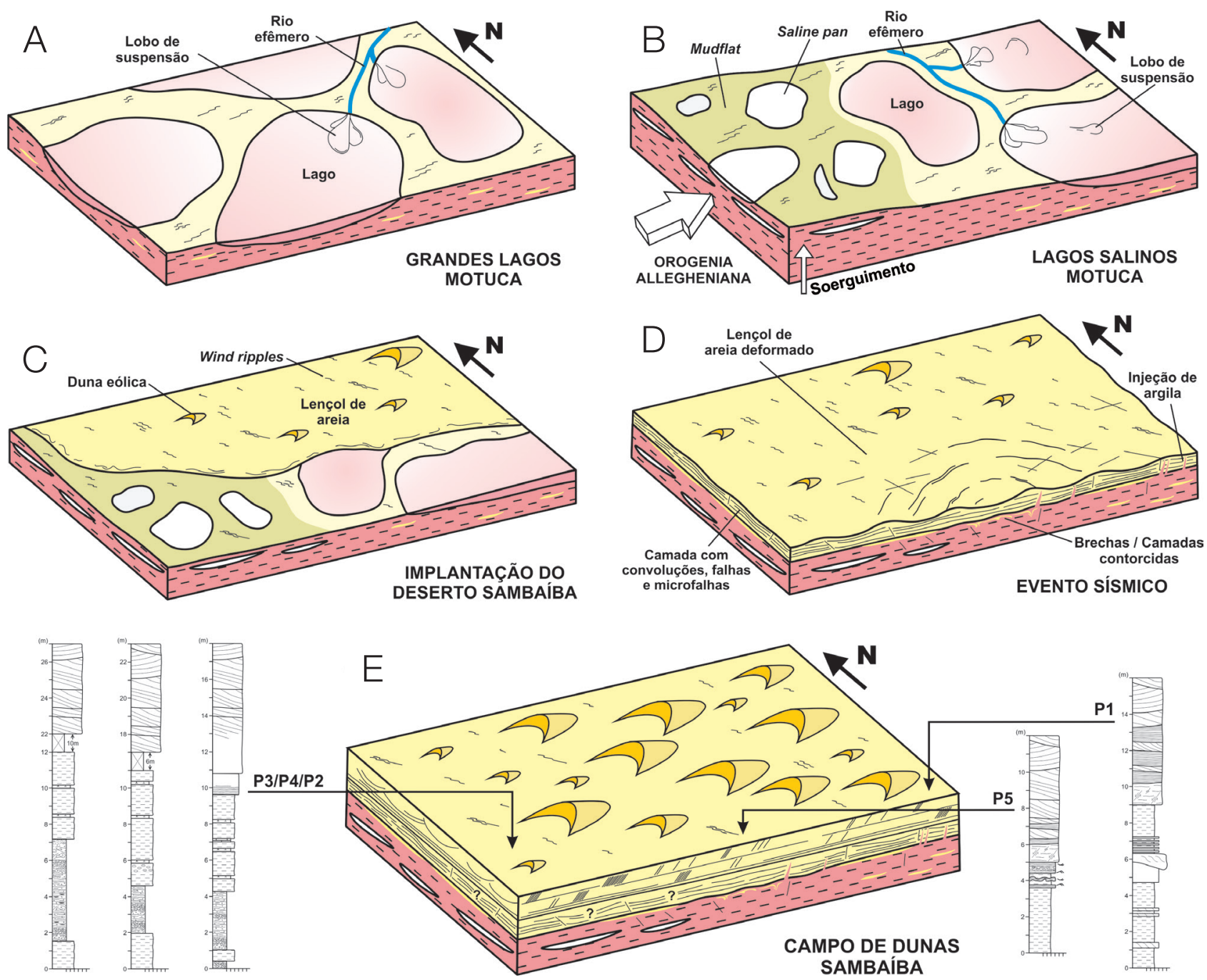

Figura 12. Modelo deposicional da passagem entre as formações Motuca e Sambaíba com a provável localização dos perfis estudados. 
intensa desertificação do megacontinente Pangeia durante o Triássico (Figura 12E), se estendendo até a Bacia do Paraná, representada pelos arenitos eólicos da Formação Piramboia (Warren et al., 2008). Essas condições exclusivamente continentais perduraram até o Jurássico, devido ao intenso magmatismo básico relacionado à tafrogênese de separação de Gondwana, que levou à abertura do Oceano Atlântico (Caputo, 1984).

\section{CONCLUSÕES}

A sucessão Permotriássica da porção centro-oeste da Bacia do Parnaíba, exposta entre as regiões de Filadélfia (TO) e Loreto (MA), foi investigada com base na análise de fácies e estratigráfica. Foram individualizadas 14 fácies sedimentares, agrupadas em 4 associações de fácies (AF), representativas de um sistema lacustre sucedido pela implantação de um sistema desértico. A AF1 e a AF2 são relacionadas aos depósitos da Formação Motuca e a AF3 e a AF4, representativas da base da Formação Sambaíba. Os depósitos lacustre raso e de mudflat da AF1 consistem em pelitos vermelhos laminados com lentes de gipsita, calcita e marga, além de lobos de arenitos sigmoidais. A AF2, interpretada como depósitos de saline pan, é constituída por corpos lenticulares de gipso laminado, gipso nodular e gipsarenito, sobrepostos por pelitos esverdeados com nódulos de dolomita e palygorskita. A AF3 e a AF4 correspondem, respectivamente, aos depósitos de lençol de areia e campo de dunas caracterizados por arenitos de coloração creme alaranjada com estratificação plano-paralela e estratificação cruzada de médio a grande porte. Intervalos deformados lateralmente contínuos por centenas de quilômetros ocorrem na zona de contato entre as formações Motuca e Sambaíba. A ocorrência conjunta de pelitos com camadas contorcidas e brechadas (Formação Motuca), arenitos com falhas/microfalhas sinsedimentares, laminação convoluta e diques de injeção preenchidos por argilitos (Formação Sambaíba) são interpretados como sismitos induzidos por terremotos de alta magnitude durante a implantação do deserto Sambaíba.

\section{AGRADECIMENTOS}

Este trabalho é parte da dissertação de mestrado do primeiro autor, financiado pelo Conselho Nacional de Desenvolvimento Científico e Tecnológico (CNPq) que concedeu uma bolsa de pesquisa. Agradecemos ao Programa de Pós-graduação em Geologia e Geoquímica (PPGG) do Instituto de Geociências da Universidade Federal do Pará pelo suporte financeiro e técnico e aos
Profs. Dr. Werner Truckenbrodt e Dr. Rômulo Angélica pelo incentivo e apoio nos trabalhos de campo e nas discussões geológicas.

\section{REFERÊNCIAS}

Aguiar, G. A. (1971). Revisão geológica da Bacia Paleozóica do Maranhão. XXV Congresso Brasileiro de Geologia, v.3, 113-122. São Paulo: SBG.

Ahlbrandt, T. S., Fryberger, S. (1981). Sedimentary features and significance of interdunes deposits. In: F. G. Ethridge, R. M. Flores (Eds.), Recent and ancient nonmarine Depositional Environments (v. 31, 293-314). SEPM (Society for Sedimentary Geology).

Bice, D. M., Newton, C. R., McCauley, S., Reiners, P. W., McRoberts, C. A. (1992). Shocked quartz at the TriassicJurassic boundary in Italy.Science, 259(1), 443-446.

Boggs, S. (2009). Petrology of Sedimentary Rocks. New York: Cambridge University Press.

Bowring, S. A., Erwin, D. H., Yin, Y., Martin, M. W., Davidek, K., Wang, W. (1998). U/Pb zircon geochronology and tempo of the end-Permian mass extinction. Science, 280(1), 1039-1045.

Bridge, J. S., Demicco, R. V. (2008). Earth surface processes, landforms and sediment deposits. New York: Cambridge University Press.

Brookfield, M. E. (1977). The origin of bounding surfaces in ancient aeolian sandstones. Sedimentology, 24(3), 303-332.

Caputo, M. V. (1984). Stratigraphy, tectonics, paleoclimatology and paleogeography of Northern Basins of Brazil. Tese (Doutorado). Santa Bárbara:University of Califórnia.

Crósta, A. P. (2002). Domo de Araguainha, GO/MT - O maior astroblema da América do Sul. In: C. Schobbenhaus, D. A. Campos, E. T. Queiroz, M. Winge, M. Berbert-Born (Eds.),Sítios geológicos e paleontológicos do Brasil (v. 1, 531-540). Brasília: DNPM/CPRM, Comissão Brasileira de Sítios Geológicos e Paleobiológicos-SIGEP.

Cunha, F. M. B. (1986). Evolução paleozóica da Bacia do Parnaíba e seu arcabouço tectônico. Dissertação (Mestrado). Rio de Janeiro: Universidade Federal do Rio de Janeiro-UFRJ. 
Cunha, P. R. C., Melo, J. H. G., Silva, O. B. (2007). Bacia do Amazonas. Boletim de Geociências da PETROBRAS, 15(2), 227-251.

Erwin, D. H. (1993). The great Paleozoic crisis: life and death in the Permian. New York: Columbia University Press.

Erwin, D. H. (1994). The Permo-Triassic extinction. Nature, 367(1), 231-236.

Erwin, D. H. (1999). Biospheric perturbations during Gondwana times: from the Neoproterozoic-Cambrian radiation to the end-Permian crisis. Journal African Earth Sciences, 28(1), 115-127.

Fryberger, S. G., Ahlbrandt, T. S., Andrews, S. (1979). Origin, sedimentary features and significance of low-angle eolian sand sheet deposits, Great Sand Dunes National Monument and vicinity, Colorado. Journal of Sedimentary Petrology, 49(3), 440-460.

Glennie, K. W., Buller, A. T. (1983). The Permian Weissliegend of N.W. Europe: the partial deformation of aeolian dune sand caused by the Zechstein transgression. Sedimentary Geology, 35(1), 43-81.

Góes, A. M. (1995). A Formação Poti (Carbonífero Inferior) da Bacia do Parnaiba. Tese (Doutorado).São Paulo: Instituto de Geociências - USP.

Góes, A. M. O., Feijó, F. J. (1994). Bacia do Parnaíba. Boletim de Geociências da PETROBRÁS, 8(1), 57-67.

Golonka, J., Ford, D. (2000). Pangean (Late Carboniferous - Middle Jurassic) paleoenvironment and lithofacies. Palaeogeography, Palaeoclimatology, Palaeoecology, 161(1), 1-34.

Jones, B. F., Galan, E. (1988). Sepiolite and Palygorskite. In: S. W. Bailey (Ed.), Hydrous Phyllosilicates (exclusive of micas) (v. 19, 631-674). Mineralogical Society of America.

Keller, G. (2005). Impacts, volcanism and mass extinction: random coincidence or cause and effect? Australian Journal of Earth Sciences, 52(1), 725-757.

Kendall, A. C., Harwood, G. M. (1996). Marine evaporites: arid shorelines and basins. In: H. G. Reading (Ed.), Sedimentary Environments: Processes, Facies and Stratigraphy (v. 1, 281-324).Londres: Blackwell Science.

Kerr, R. A. (1996). A shocking view of the Permo-Triassic. Science, 274(1), 1080.
Kocurek, G., Havholm, K. G. (1993). Eolian sequence stratigraphy: a conceptual framework. In: P. Weimer, H. W. Posamentier (Eds.), Siliciclastic sequence stratigraphy: recent developments and applications (v. 52, 393-409). SEPM Special Publication.

Melo, M. T., Prade, G. O. (1968). Geologia da região Sudeste de São Raimundo das Mangabeiras - Maranhão. Belém: Relatório 297M PETROBRÁS, DIREX/RENOR.

Miall, A. D. (1991). Hierarchies of architectural units in terrigenousclastic rocks and their relationship to sedimentation rate. In: A. D. Miall, N. Tyler (Eds.), The three-dimensional facies architecture of terrigenousclastic sediments and its implications for hidrocarbon discovery and recovery (v. 1, 6-12). Tulsa, Okla: SEPM (Society for Sedimentary Geology).

Miall, A. D. (1994). Reconstructing fluvial macroform architecture from two-dimensional outcrops: examples from the Castlegate Sandstone, Book Cliffs, Utah. Journal of Sedimentary Research, 64(1), 146-158.

Mountney, N. P. (2006). Eolianfacies models. In: H. W. Posamentier, R. G. Walker (Eds.), Facies models revisited (v. 1, 19-83). Tulsa, Okla: SEPM (Society for Sedimentary Geology).

Parrish, J. M., Parrish, J. T., Ziegler, A. M. (1986). Permian-Triassic Paleogeography and Paleoclimatology and Implications for therapsiddistributions. In: N. H. Hotton, P. D. McLean, J. J. Roth, E. C. Roth (Eds.), The ecology and biology of mammal-like reptiles (v. 1, 109132). Washington: Smithsonian Press.

Plummer, F. B., Prince, L. I., Gomes, F. A. (1948). Estados do Maranhão e Piauí. Rio de Janeiro: Relatório do Conselho Nacional do Petróleo.

Postma, G. (1990). Depositional architecture and facies of river and fan deltas: a synthesis. In: A. Colella, D. B. Prior (Eds.), Coarser-grained deltas (Special Publication, 2974). Londres: Blackwell Science.

Retallack, G. J., Seyedolali, A., Krull, E. S., Holser, W. T., Ambers, C. P., Kyte, F. T. (1998). Search for evidence of impact at the Permian-Triassic boundary in Antarctica and Australia. Geology, 26(11), 979-982.

Rodríguez-Pascua, M. A., Calvo, J. P., De Vicente, G., Gómez-Gras, D. (2000). Soft-sediment deformation structures interpreted as seismites in lacustrine sediments of the Prebetic Zone, SE Spain, and their potential use as indicators of earthquake magnitudes during the Late Miocene. SedimentaryGeology, 135(1), 117-135. 
Salvany, J. M. (1997). Continental evaporitic sedimentation in Navarra during the Oligocene to Lower Miocene: Falces and Lerín Formations. In: G. Busson, B. C. Schreiber (Eds.), Sedimentary Deposition in Rift and Foreland Basins in France and Spain (Paleogene and Lower Neogene) (v. 1, 397-411). New York: Columbia University Press.

Schreiber, B. C., El Tabakh, M. (2000). Deposition and early alteration of evaporites. Sedimentology, 47(1), 215-238.

Scotese, C. R., Bouco, T. A. J., Mckerrow, W. S. (1999). Gondwana palaeogeography and palaeoclimatology. Journal of African Earth Sciences, 28(1), 99-114.

Sepkoski, J. J. (1986). Global bioevents and the question of Periodicity. In: O. Wallisser (Ed.), Lectures Notes in Earth Science (v. 8, 47-61). Global Bio-events.

Steiner, M. B., Eshet, Y., Rampino, M. R., Schwindt, D. M. (2003). Fungal abundance spike and the PermianTriassic boundary in the Karoo Supergroup (South Africa). Palaeogeography, Palaeoclimatology, Palaeoecology, 194(1), 405-414.

Talbot, M. R., Allen, P. A. (1996). Lakes. In: H. G. Reading (Ed.), Sedimentary Environments: processes, facies and stratigraphy (v. 1, 83-124). Londres: Blackwell Science.

Tlili, A., Felhi, M., Montacer, M. (2010). Origin and depositional environment of palygorskite and sepiolite from the ypresianphosphatic series, southwestern. Clays and Clay Minerals, 58(1), 573-584.

Tohver, E., Lana, C., Cawood, P. A., Fletcher, I. R., Jourdan, F., Sherlock, S., Rasmussen, B., Trindade, R. I. F., Yokoyama, E., Souza Filho, C. R., Marangoni, Y. (2012). Geochronological constraints on the age of a Permo-Triassic impact event: U-Pb and ${ }^{40} \mathrm{Ar} /{ }^{39} \mathrm{Ar}$ results for the $40 \mathrm{~km}$ Araguainha structure of central Brazil. GeochimicaetCosmochimicaActa, 86(1), 214-227.
Tucker, M. E. (1991). Sedimentary Petrology: an introduction to the origin of sedimentary rocks. Londres: Blackwell Scientific Publications.

Twitchett, R. J., Looy, C. J., Morante, R., Visscher, H., Wignall, P. B. (2001). Rapid and synchronous collapse of marine and terrestrial ecosystems during the end-Permian biotic crisis. Geology, 29(1), 351-354.

Vaz, P. T., Rezende, N. G. A. M., Wanderley Filho, J. R., Travassos, W. A. S. (2007). Bacia do Parnaíba. Boletim de Geociências da PETROBRÁS, 15(2), 253-263.

Velde, B. (1985). Clay Minerals: a Physico-Chemical Explanation of their Occurrence. Developments in Sedimentology, 40(1), 225-256.

Walker, R. G. (1992). Facies, facies models and modern stratigrahic concepts. In: R. G. Walker, N. P. James (Eds.), Facies Models - Response to Sea Level Change (v. 1, 1-14). Ontario, Canada: Geological Association of Canada.

Warren, J. K. (2006). Evaporites: Sediments, Resources and Hydrocarbons. Berlim: Springer.

Warren, L. V., Almeida, R. P., Hachiro, J., Machado, R., Roldan, L. F., Steiner, S. S., Chamani, M. A. C. (2008). Evolução sedimentar da Formação Rio do Rasto (PermoTriássico da Bacia do Paraná) na porção centro sul do estado de Santa Catarina, Brasil. Revista Brasileira de Geociências, 38(2), 213-227.

Wilson, I. G. (1971). Desert sandflow basins and a model for the development of ergs.Geographical Journal, 137(1), 180-189.

Zalán, P. V. (1991). Influence of Pré-Andean orogenies on the Paleozoic Intracratonic Basins of South América. IV Simpósio Bolivariano, v. 1, n. 7. Bogotá.

Zharkov, M. A., Chumakov, N. M. (2001). Paleogeography and Sedimentation Settings during Permian-Triassic Reorganizations in Biosphere. Stratigraphy and Geological Correlation, 9(4), 340-363. 